\title{
Estonian Male Journalists' Experiences with Abusive Online Communication
}

\author{
Armas Riives, Maria Murumaa-Mengel, Signe Ivask
}

\begin{abstract}
Several studies have established that female journalists experience (sexual) harassment and online abuse considerably more than their male colleagues. Understandably, this has resulted in a gap in research - male journalists' experiences with abusive online communication have not yet been thoroughly studied. This paper seeks to understand how abusive communication is contextualised and defined by male journalists in the context of hegemonic masculinity, and to explore which coping strategies are employed to overcome such experiences. From qualitative in-depth interviews with male journalists $(n=15)$, we found that participants considered different forms of abusive online communication from readers/sources a normalised practice, "feedback" that one must just ignore or overcome. Experiences are interpreted predominantly in the frame of hegemonic (complicit) masculinity, but the results also indicate that shifts in these rigid norms are emerging and can be embraced when acknowledged and supported by surrounding structures.
\end{abstract}

KEYWORDS male journalists, abusive online communication, masculinity, coping strategies, journalism

\section{Introduction}

The very recent global crises have caused plummeting record-low levels of trust in traditional media, news sources and journalists (Edelman 2021). According to the latest Edelman Trust Barometer, we are currently in an environment of information bankruptcy and people do not know where or from whom to get reliable information. In these turbulent times, anti-press and anti-journalism discourses have prevailed (Shin et al. 2020) and journalists are often the targets of multifaceted hate speech (Obermaier et al. 2018).

To take a few steps back, we must acknowledge the immense potential that networked information societies have for journalism. Social media platforms, easy access to emails and/ or phone numbers, and comments sections in online news have broadened the possibilities for audience members to participate in larger public discussions, but also enable more private dialogues with journalists (Hedman and Djerf-Pierre 2013). Besides having positive effects on the media and reporting, these opportunities can be reframed as risks, particularly for journalists themselves. At the core of this article's problem setting is the fact that journalists are routinely exposed to the many faces of abusive online communication, such as

Sociálnístudia/Social Studies 2/2021. S. 31-47. ISSN 1214-813X. https://doi.org/10.5817/SOC2021-2-31 
harassment, aggression, negative feedback (Ivask 2020), bullying (Gudipaty 2017), verbal threats, defamation, trolling (Reynard 2019) and different methods of online shaming (Detel 2013).

We will mainly use the term "abusive online communication" throughout this article, as it allows us to talk about a myriad of cases and navigate the terminologically messy nature of such negative experiences. By abusive online communication we mean a broad spectrum of computer-mediated communication - whether it be on a public forum or via more private email - that is occurring in a deliberately insulting or offensive way and involves an explicit or implicit challenge to a person's perceived safety (Law Commission 2018). Although we specifically focus on online platforms, it is worth emphasising that the boundaries of onlineoffline spheres are often imaginary.

So far, several studies (e.g. North 2016; Löfgren Nilsson and Örnebring 2016; Chen et al. 2018) have established that female journalists experience (sexual) harassment and abusive communication considerably more often than their male colleagues. This understanding has inspired important scholarly work on how female journalists perceive, experience, and cope with such harassment and abuse (e.g. Hardin and Shain 2006; Adams 2018; Ivask 2020). However, male journalists' experiences with abusive online communication have not yet been adequately studied. Perceived masculine stereotypes might hinder male journalists in reporting and defining harassment and abuse as such, thus further hiding the problem from sight and reinforcing said stereotypes.

Although we focus on journalists in this article, the broader discussion involves many other professions - after all, information society's general ideals have been and are framed by the central values of accessibility, transparency and interactivity (Webster 2014). Whatever is happening to journalists could be an indicator of what is to come (or is already happening) for many other professions. In Estonia, for example, verbal attacks and abusive online communication against journalists have been growing as a social problem for at least a decade, and in recent years similar discourses have become evident in the cases of medical workers, scientists, teachers etc.

Estonia serves as a relevant example for a couple of reasons. First, it is often referred to as a super-connected liberal "e-state" (Metcalf 2019), with most Estonians used to technology being integrated in their everyday lives and incorporated into their daily routines and communication habits (Pärson 2018). This means that most people have fulfilled the minimum requirements and possess the digital skills to engage in (abusive) online communication. Furthermore, Estonia is considered a country with a strong position in the World Press Freedom Index, according to Reporters Without Borders, usually placing in or near the top 10, suggesting that journalists are generally free and able to do their job.

But on a more critical note, in terms of gender equality and stereotypes, we see societal issues that somewhat contradict the innovative super-connected contemporary e-state narrative. Estonia is at the very bottom group of EU countries when it comes to indicators of gender equality, ranking eighteenth in the EU on the Gender Equality Index. To name a few notable factors for the indirect context of this study: the gender pay gap is over $17 \%$ (Statistics Estonia 2019); although the undereducated part of the population is predominantly made up of men, women are still at a disadvantage in the labour market (EIGE 2018); gender 
equality and feminism are still largely perceived as tools and principles which work mainly in favour of women; and rigid gender stereotypes persist, especially in older generations' perceptions and beliefs (Marling 2017). Obviously, hegemonic masculinity and gender inequalities persist not only in Estonia - similar attitudes, behaviours and patterns can be observed in other countries as well.

Overall, this article aims to explore and understand male journalists' experiences and ways of coping with abusive online communication within the context of gender norms. The results of our qualitative interview-based study with Estonian male journalists $(n=15)$ point to a worrying trend of recontextualisation of abusive online communication as part of the journalistic professional routine and even as "feedback" or media criticism. We found that male journalists are likely to be affected by ridicule and comments that target their masculinity and have developed several coping strategies. The interviewed journalists expressed fatigue and the need for psychological support, currently lacking in media organisations.

\section{Theoretical Framework and Background for the Study}

\section{Contemporary Journalists' Work-life: From Societal Structural Pressures to Personal Attacks}

Rapid changes in technology and the widely accepted norm of accelerated social life (Rosa 2013) have considerably changed how journalists work and their routines - they are affected by time-pressure, productivity-pressure, and the norm of availability from sources, colleagues, and fragmented audiences. The prevalent effectiveness-oriented alwaysproductive ideal of work-life is a macro-manifestation of widely accepted traditional masculinity traits. Public and private spheres are gendered, with the masculine public being valued and privileged over the feminine private (Fletcher 1998: 165). Thus, we see that emotional well-being and the value of the private sphere is in the background. Although technological changes have allowed greater autonomy and flexibility in professional spheres, "there is simultaneously the risk of an encroachment of work-life on private life" (Krause 2018). Furthermore, work and work-related communication knows no boundaries, which also means harassment, negative feedback, and abuse knows no boundaries.

Aggressive and abusive online communication towards journalists is nothing groundbreakingly new. For example, a large number of Swedish journalists have said that they face such comments on a regular basis; $10 \%$ of them report receiving aggressive comments weekly (Löfgren Nilsson and Örnebrings 2016: 883). Similar numbers and trends are visible in other countries, as well (Luque and Koponen 2017). Journalists are more reachable by their audiences than ever before: their contact information is public, their photos and office hours as well, and many use personal social media accounts for sharing journalistic content and opinions, gathering potentially large followings.

Online communication has specific characteristics that make abusive and offensive communication prevalent, e.g. toxic disinhibition (Suler 2005) in communication and the perceived cloak of anonymity. The offender might not have any social cues, social control, or potential to be sanctioned to keep their behaviour in check (Citron 2014). There 
seems to be a sort of "abuse in numbers" mentality as well - Citron (2014) has pointed out that in online spaces, offenders feel emboldened by acting alongside others who share a desire to communicate in an offensive or abusive way, as the communication norm is perceived to be aggressive. We follow a definition where abusive communication is any offensive, threatening, or aggressive verbal expression and behaviour where the attacked person perceives themselves to be in an uncomfortable, tense, or stressful situation (cf. Fortuna et al. 2020).

The content of such abusive interactions can focus on many aspects of the journalist's work or persona, but usually competence and intelligence are questioned: two aspects that might not seem severe but could affect journalists' self-perception, professional life, and health negatively (Löfgren Nilsson and Örnebring 2016: 885; Ivask 2020). The aggressive comments could vary from calling the journalists by an insulting name to threatening them with violence or death. It is important to note that these threats can actualise, as many tragic cases have proven. Online abuse can result in emotional, psychological, physical, reputational, or other kinds of harm in the socially and technologically augmented lifeworlds of people.

Attacks and threats can be used to silence journalists as a systematic method of intimidation, impacting the way journalists cover a topic or how stressed they feel in their professional life, possibly leading to changing careers (Löfgren Nilsson and Örnebring 2016). In other words, how audience members communicate with journalists has a substantial effect on what kinds of topics are covered and how stories are presented (Lee and Tandoc 2017: 438), and how much self-censorship is applied (Ivask 2020).

\section{Coping with Personal Attacks and Negative Feedback}

Journalists' experiences with aggressive audience members have intensified in recent years, which is why journalists need coping strategies to deal with the potentially traumatic or at least disturbing experiences (Post and Kepplinger 2019). Journalists who face a lot of negative feedback and aggression from readers in comment sections might be perceived as less credible among their readers, or the journalists may feel less recognised and valued than their colleagues (Post and Kepplinger 2019: 2433). Broadly speaking, there are three main ways that journalists cope with challenging experiences of online communication, according to Post and Kepplinger (2019: 2425): (1) a problem-focused coping strategy where the journalist tries to suppress the aggressive stressor and defend oneself against the humiliation; (2) an emotion-focused coping strategy where the journalist tries to approach the stressor constructively; and (3) an avoidance-type coping strategy that is often considered dysfunctional - e.g. the journalist ignores the stressor, gives up previous goals or attitudes, and does not work through the issue. Journalists turn to diversion strategies if they lack skills or knowledge about how to overcome a traumatic situation. For example, using dark humour to make light of the situation, tempering their emotions and memories, (over) exercising, focusing on the technicalities of the situation, or using substances (Buchanan and Keats 2011), all contributing to the "thick skin" discourse culture in newsrooms. 
If we zoom in on the coping strategies that align with traditional hegemonic masculinity (Connell 1987) - the dominant, culturally idealised and preferred manhood - we see that even acknowledging the existence of a problem related to well-being is in conflict with traditional gender norms. Robertson (2007) argues that the traditional model prescribes that men not show interest in their own (mental) health, because it is framed as a feminised concern. Thus, the stereotypically masculine man should cope on his own and handle situations without help. But as Goldberg (1976: 68) pointed out, when men's emotional inhibition is too high and if men continue to block out their emotions, it will likely lead to risky behaviours, such as excessive alcohol consumption, dangerous driving, or violence towards others. Because hegemonies are taken-for-granted as natural and universal, they elicit voluntary compliance and obedience (Tsuda 2020), escaping even everyday reflection and awareness on the matter.

\section{The Gendered Nature of Abusive Online Communication}

Online abuse is experienced in an ambivalent space that is simultaneously private and public, as social media platforms offer opportunities for performative communication before large masses, but also one-to-one communication situations (Lewis et al. 2017). Jane (2015: 76) adds that in many instances and from some perspectives, the generation and circulation of online abuse and e-bile "can be pleasurable, cathartic, creative, entertaining, funny, performative, subversive, educational, empowering, part of a strategy of counterhegemonic resistance". But mostly, aggressive and/or hostile communication occurring online (O'Sullivan and Flanagin 2003) is very often heavily gendered - explicitly sexist, sexualised, threatening and violent behaviour directed largely at women online (Lewis et al. 2017) which may in fact restrict women's civic engagement (Citron and Norton 2011).

In the context of this article, it is essential to ask whether experienced online abuse depends on the gender of the journalist and what role gender stereotypes play in journalistic work. Shanahan (2017) and Chen et al. (2018) point out that women experience bullying, abuse and aggression considerably more often than men. Additionally, it is not just quantitative differences - for women, the content of the aggression tends to be different as well. Every other female journalist has experienced sexual harassment, and while one in seven women has experienced physical harassment, eight in ten of them did not report the incident at all, out of fear of making the experience more traumatic for themselves (Reporters Without Borders 2017). Hardin and Shain (2005: 28), in their study of female sports journalists, showed that female journalists must endure sexist comments from readers and colleagues at work, and in some cases sources explicitly ask to speak with male reporters instead of them.

Similar tendencies and problems are evident in online communication - female journalists often receive sexist comments, mainly using the word "slut" or an equivalent, as confirmation of misogyny (Ivask 2020). It is reported that $15 \%$ of female journalists have also experienced being threatened in online commentary with rape, genital cutting or other forms of serious sexual violence (Löfgren Nilsson and Örnebring 2016: 885-886). In fact, many (cf. Jane 2014; Ziegele et al. 2017) argue that violent e-bile, misogynistic hostility, and heavily gendered vitriol has become lingua franca in most online spaces. According to 
Citron (2009: 377), when harassment and abuse are viewed and called out specifically as that, rather than as a trivial issue, women are more likely to talk about their experiences publicly, instead of suffering in silence. The same could be said for all genders.

If we turn our attention to male journalists, and to men and masculinities in a broader sense, we could argue that such discussions around the abuse and harassment of men cannot happen in a similar way. Hegemonic narrow stereotypes of traditional masculinity, still rooted in static social structures, usually leave no accepted ways to call out and contextualise such instances as serious offences. The self-sufficient, strong and non-emotional masculine leader archetype dominates (Robinson 2000) and frames the repertoires that dictate how, and if at all, men talk and feel about abuse and harassment. Any hint at victim status does not align with the Western normative cultural image of men, which is associated with strength and control (Burcar 2014). Hegemonic masculinity stems from characteristics attributed to men in power and therefore perpetuates their dominance through the subordination of women as well as non-dominant men (Tsuda 2020).

Robinson (2000: 128-129) also calls such hegemonic masculinity a kind of "blockage" by which men are forced to repress, suppress and oppress their emotions as the main coping mechanisms, and as a result, "male bodies and minds are on the verge of shutting down". Robinson (2000: 131) points out that discussions around men's liberation and patriarchal power have led to the emergence of alternative masculinities but also to the much-derided "sensitive man" emerging from the discussion and becoming a joke. Thus, the so-called "sensitive man" or "soft male" has become the opposite of the Western normative culture of men and recreates the hegemonic masculine culture. Noticeably often, aggressors use online social spaces, textual and visual cues to signal a masculine self, enforce hegemonic gender norms, oppress women, and keep men "in the box" (Moloney and Love 2018). However, suppressing and dealing with negative emotions without psychological help can hurt emotional well-being. Mental health issues are often framed as emotion-based and thus unmasculine, building tension and barriers to help-seeking processes, as hegemonic masculinity is constructed in opposition to femininity (McKenzie et al. 2018).

Recent studies have confirmed that nearly all journalists experience at least some online harassment, irrespective of gender, but that such harassment is generally infrequent overall, especially its most severe forms (Lewis et al. 2020). Because women generally experience and report much higher incidences of online harassment than men (Stahel and Schoen 2020), the focus has been on women. This means that we lack knowledge whether and how men are potentially "kept in a box" (Moloney and Love 2018) as a result of online abusive communication in the context of journalism. Since male journalists' experiences with abusive online communication have not yet been thoroughly researched, we set off with three main research questions in mind: (1) What kinds of experiences do male journalists have with abusive online communication, and how do they define and frame the scope of such communication? (2) How are these experiences interpreted and reconstructed in the context of gender? (3) Which coping strategies do journalists use to deal with abusive online communication in a professional setting? 


\section{Participants and Methods}

We invited Estonian male journalists to participate in the study by circulating the call in all major media houses and in our professional networks. In the call we did not emphasise the criterion of having had experiences with abusive online communication, as we aimed to have a broader conversation, in addition to discussing personally lived experiences. We set no limiting participation criteria other than gender.

All of the participants $(n=15)$ work in converged newsrooms, where journalists do not only work for print, but also online, audio and/or audiovisual outputs. Their ages vary from 24 to 60, and the length of professional journalistic experience spans from two to thirty years. We use codes for the interviewees (e.g. M_42) where the number indicates the age of the interviewee. The participants' educational backgrounds vary greatly as well: some interviewees have advanced degrees in journalism and communication; some have a degree from other disciplines; some did not attend university. Many of the interviewees do not have a particular beat or specialisation, but most have expertise and routinely cover a particular field - e.g. politics, economics etc.

The sample does have some limitations and inherent homogenous characteristics due to the Estonian context. The country is not very heterogeneous in terms of ethnic minority groups: the general population is roughly composed of 70\% Estonians, 25\% Russians, and 5\% other ethnic nationalities, according to Statistics Estonia (Kütt 2021). All the participants in our study were either native Estonians or of a mixed Estonian-Russian background.

The data were collected by the first author of this article (pronouns he/him) via qualitative face-to-face semi-structured interviews that took place in 2018 and 2019. The interviews were set up to take place in familiar settings - usually at the journalists' workplaces, using quiet rooms and separated individual workspaces to ensure privacy. The interviewer shared some identifying markers with the participants - the same gender and profession. In other words, we embraced the fact that researchers are not fixed in their objective observerposition but rather continuously moving back and forth between insiderness and outsiderness (Griffith 1998). Qualitative research methods are also fitting for the approach of social constructivism embedded in gender studies, with the underlying assumption of a plastic and pluralistic world where meanings are constructed by constant social interaction, by nature shared and collaborative (Berger and Luckmann 1966).

The approximately hour-long interviews covered different overarching topics (negative and hostile feedback from various actors; perceived reasons for it; coping strategies; constructed potential effects on journalism). We anticipated that the topic of our study would be perceived as sensitive by some participants (Dickson-Swift et al. 2007), whether openly admitted or not, as "sensitivity is perceived in the eye of the beholder" (Zanjani and Rowles 2012: 400). That is why the interviewer took extra care to be empathic, and to ensure the quality of the collected data by using specific interviewing techniques that reflect and specify the answers given, occasionally sharing personal stories to make participants feel more comfortable (Berger 2001). Additionally, he avoided labelling and defining various behaviours (e.g. did not use terms like "harass", "abuse" or "aggression" before the interviewee had used a specific term himself), as language carries different connotations for different genders. 
The interviews were transcribed, anonymised and then analysed using within-case and cross-case thematic qualitative text analysis (Braun and Clarke 2006), whereby researchers are able to identify "what is common to the way a topic is talked or written about and of making sense of those commonalities" (Braun and Clarke 2006: 57). The data were read repeatedly to obtain a holistic sense of the text, with the first step being "immersion" (Braun and Clarke 2006). After forming initial codes, each new case - part of the text - was compared to previously coded ones, trying to find common ground where possible, and if necessary a new topic category was created. After close readings and initial open coding, we approached the cases in-depth and tried to find and understand the latent meanings and attitudes in the interviewee's words and descriptions. Selective coding, keywordbased double-checking and subsequent modifications generated an increasingly consistent and logical structure to the analysis.

\section{Results and Discussion}

\section{Defining and Describing Experienced Abusive Online Communication}

The majority of Estonian online news platforms accept anonymous comments in their comments sections, which has led to intensive "trolling" and vulgarities under the label of freedom of speech (without responsibility), adding stress to journalists' work. Most participants in our study were quick to acknowledge having frequent experiences with abusive online communication, as it seems to be the norm in online environments that allow anonymity. It was noticeable that the journalists did not use "harassment", "bullying", "abuse" or any other terms to define these experiences. The preferred term was "negative feedback", which is arguably a very neutral expression, considering the seriousness of such interactions in some cases.

This can be interpreted as a coping strategy since "feedback" is usually used in productive work-related discourses; thus, the interviewees made an (un)conscious decision to contextualise abuse as something that can be valuable and placed in the mental compartment of business-as-usual, to avoid the necessity of more in-depth reflection or emotional responses. Another way of talking about abusive communication was to define it as an "emotional outburst" or "arbitrary rumbling" - trivialising the act and expressing the masculine-rational framework of overcoming it.

Journalists said such hostility usually comes from either the "general newsreader" or, more specifically, a source from their article. Our interviewees tend to stay away from the comment sections, as there is seldom meaningful dialogue and they do not want to waste time, as is suitable to the efficient accelerated (Rosa 2013) workflows. But despite labelling these spaces not constructive and pointless, participants sometimes admitted to browsing the comments "out of curiosity" - viewed as a sort of a guilty pleasure of snooping or giving in to the temptation.

Journalists are fairly used to being publicly shamed and bashed on people's personal social media pages as well, as it is common to come across long tirades about their persona, political ties and biases, and lack of morality and ethics. In addition to the comments sections 
and blog or social media posts, interviewees also described direct communication practices where readers seek out a journalist on social media (predominantly Facebook) or write them a personal email and pour out their anger. Some typical examples of such interactions were phrased as "set yourself on fire!", "you idiot and an ignorant snowflake" or "find another form of expression for your meaningless scribbles". Noticeably, straightforward sexism and threats of sexual violence are missing from the descriptions, which is typical of the abuse that women get (Lewis et al. 2017; Jane 2014). The constructed examples also hint at a typology of how male journalists are targeted: by questioning their skills/competence, knowledge/education and age/generation, three categories similar to what Löfgren Nilsson and Örnebring (2016) have found. The main insult type was described as a stab directed at their intelligence and education:

Usually they throw something simple at you, like asking what degree you have and then following with a "that is what I thought - you are stupid" comment. (M_43)

In our interviews, the journalists said that if negative and hostile feedback comes from an anonymous source, it is especially unpleasant - the "cloak of invisibility" makes it impossible to use confrontational emotion-focused coping strategies (Folkman and Lazarus 1988; Post and Kepplinger 2019).

One way of receiving such "feedback" is via general mailing lists that include everyone in the newsroom. Anonymous hostile and negative feedback is often sent to the general list, where everyone can witness it, increasing the potential of public shame:

It makes me aggravated, knowing that someone can write anonymously, that someone can mock us that way. It is upsetting, creating unnecessary stress. (M_61)

The semi-public setting increases the performative aspect of the act and such punitive use of mockery and ridicule are argued to be a powerful strategy of social control for policing hegemonic masculinities (Abedinifard 2016). There is even a popular quote, attributed to writer Margaret Atwood, stressing the male fear of mockery: "Men are afraid that women will laugh at them. Women are afraid that men will kill them."

Returning to the "Snowflake" label: it is a great example of how someone's masculinity can be called into question, as the stereotypical "Snowflake" represents characteristics traditionally not attributed to hegemonic masculinity and gender norms - easily-offended, emotional, empathetic, left-leaning. Usually, these comments seem to come from older people, where it is also a manifestation of juvenilia, generational value conflicts and divides. Younger journalists are called "teenagers" or "punks" who have not really experienced life yet. Studies have pointed out (Lewis et al. 2020; Löfgren Nilsson and Örnebring 2016) the pattern where abusive and hostile comments from the audience tend to emphasise the age of the journalist. And to some effect, according to our study - younger interviewees described themselves as being more influenced, paying more attention and responding actively to all sorts of feedback. The communication norm of younger generations reflects the constant availability expectation and the domestication of communicative dialogical platforms and technologies (Murumaa-Mengel and Siibak 2019). In terms of masculinity - it is perhaps a slow shift toward more open communication standards, instead of the saying-less-is-more 
standard to avoid tainting the embodiment of hegemonic masculinity with non-compliant "chattering of the old wives".

Notably, some cases and examples were contextualised as more serious, closer to the "true and real abuse" category. Several journalists said that they have received direct threats of physical violence, including death threats, and these are taken much more seriously. A recurring common narrative indicated that such threats and abuse is expected when covering crime-related topics. Usually, the commentators seem to be involved in these cases somehow and via abusive online communication try to manipulate and scare the journalist:

He even asked if he has to find me - "you, little shit" - that small threat was already scary /---/ I also accidentally left my phone number in the signature of my email and he called me. I blocked his number, and the situation was resolved. (M_26)

The repeated calls, comments or emails were more likely to be termed "harassment" by the participants, as it held to a repetitive pattern of action.

\section{Perceived Gender-Based Differences in Abusive Online Communication}

On an abstract level, the interviewed male journalists expressed the belief that journalism as a profession is gender-equal: there are no significant differences between male and female journalists in their work practices and their success. As has been pointed out in influential works, most men do not embody and enact hegemonic masculinity; "complicit masculinity" is a more passive way of reproducing social order, benefitting from its patriarchal dividends (Connell 1987; Goldberg 1976; see also Tsuda 2020). And indeed, it could as appear that the playing field is levelled - female journalists make up nearly $60 \%$ of the profession in Estonia (Worlds of Journalism 2016) and the most prestigious journalism prizes, the annual Bonnier Awards for investigative journalism, have been awarded to roughly 50\% women and $50 \%$ men over the past 25 years. Over the course of the interviews, though, most male journalists said they had heard of or seen their female colleagues not being taken seriously as journalists, simply because of their gender.

Several of the interviewed journalists acknowledged the "white man" standard and privilege that is often left unchallenged, and all who display some sort of "otherness" from that standard are more vulnerable to attacks. Hegemonic masculinity may lead to the patriarchal domination of women, but also of subordinate (minority) men, thus reproducing different inequalities (Tsuda 2020). In our journalists' opinions, most of the abusive online communication comes from white middle-aged men, dedicated to maintaining the status quo of social order - similarly to the results of previous research (Ziegele et al. 2017; Post and Kepplinger 2019).

In the previous section we described the dominant ways how men are being insulted by readers and sources, here the interviewees pointed out over and over again female journalists are consistently called and labelled as "missy" or "young girl" who could not possibly comprehend the complex world. In addition to the Stupid Bimbo stereotype, Evil Witch stereotype was also described to be present in the attacks against women. For example, one notable story that was told during the interviews was about a press conference where 
a female journalist had been told publicly and directly: "Lord, what a witch you are". Some male journalists also pointed out that they had felt like female sources or commentators were trying to play on these stereotypical traits and "strengths" and take advantage of their masculinity and gender:

There are some weird [flirtatious] moments where I am practically starting to think, "Wait, wait, now I don't understand exactly whether they like me, or what exactly they want from me". And the most paranoid idea is always whether their goal is to make me show them in a better light. (M_27)

Our participants had not heard their female colleagues talk about sexual harassment cases, but they have heard plenty about the normalised hostile and aggressive "feedback". The ideal hegemonic masculinity values were evident in how these incidents and discussions around them were phrased. Our male journalists said that they had not, nor had their female colleagues, "complained" about the abusive online communication. This further strengthens the stereotype of the strong, silent, rational male ideal coping discourse.

And the interviewed male journalists are often aware of these (unjust) pressures of hegemonic masculinity - they described the stress of having to behave as if the abuse does not affect them, the expectation of having to cope on their own and not seek help from their peers or organisation. As women are traditionally and gender-stereotypically entitled to expressing more emotions than men (Robinson 2000), their abuse is more visible and discussed, whilst men are supposed to have an extra-thick layer of skin in this profession. The work here shows that male journalists, too, receive a lot of hostile feedback, but minimise and normalise it and its impact on their work.

\section{Coping Strategies and Perceived Effects of Abusive Online Communication}

The issue of "thick skin" came up throughout the interviews. When talking about multifaceted coping strategies that can be applied in situations involving abusive online communication, the reactions and strategies employed were perceived to depend on the "thickness of the skin" and not gender per se. Stress tolerance, conflict-management skills and willingness to confront the abuser were also named as factors influencing the choice of how to react.

Journalists are usually highly trained in information-seeking skills, so it is no wonder that they make use of those literacies in the context of handling abusive non-anonymous online communication. When someone attacks them online, a common way to cope is Googling. Journalists seek additional information from search engines and social media to gain a sense of control and "measure up" their opponent. Looking up where the person lives, what they look like, what their usual posts and comments are about etc. helps journalists to assess whether it is worth taking the "feedback" seriously. The more common and ordinary, the less influence - or, conversely, the higher the social status (e.g. politicians, an expert in a certain field, military officers etc.), the more influence on the journalist.

Journalists mostly voiced a shared understanding that unjustified negative feedback can ruin their day. And if there are enough such days, some discussed the thought of leaving the field for good: 
Should I be the punching bag for someone while I just grit my teeth... while I still have a head and two hands, sure I will be fit for other professions than the press. (M_45)

I have dark thoughts quite often - thought of not being able to do as good as expected in the newsroom. Or fear of making mistakes, and from time to time I have the feeling that I should go somewhere to be a security guard, to do a more straightforward job where you don't have to think about such things, you would just have to do your simple thing, move the box to a different place. (M_61)

Here we see examples of avoidance-based coping mechanisms expressed as potential future possibilities - strategies where the journalist ignores the stressor, gives up previous goals or attitudes, and does not work with the issue (Post and Kepplinger 2019: 2425).

But mostly, consistent abusive (online) communication is brushed off, as described in the first part of the results above. If it is frequent enough, though, self-doubt increases. Questions like "should I write about it?", "what if I messed up?" and "whom should I turn to as a source and whom to avoid?" were described as resulting from long-term and multiple negative interactions:

I would not call it self-censorship, but it might make me more careful in fact-checking, writing down, and interpreting quotes. Through the process, you have to critically think and reflect if you have got it right this time. (M_27)

Similarly to Ivask's (2020) study among Estonian women journalists, we found that male journalists avoided using the term "self-censorship", as the connotation is straightforwardly of something forbidden and unprofessional, possibly a reminder of Soviet times. Ivask (2020) goes on to say that self-censorship hinders fulfilling the journalists" "watchdog" role.

Confrontational coping strategies are employed daily, as it is somewhat "part of the job", especially when the abusive and aggressive communication comes from a known source. But this does not mean in any way that these kinds of interactions leave the journalists unaffected. The main emotions described are rage and anger, once again fitting with the accepted reactions in the context of hegemonic masculinity:

I turn off myself briefly and stare at the computer, clearing all thoughts. I am just zoning out, and then I will talk about what happened. I cannot speak immediately afterwards because I will raise my voice. It affects you emotionally in some ways and is transmitted to you. I cannot believe it even right now telling you this all makes me angry. Therefore, those moments are emotionally difficult, but then you take a few moments to calm down, and then you might just tell a colleague what just happened. (M_27)

We see from the last sentence that communicative coping strategies do make an appearance in the interviews - not often, but still. Sincerely asking for help is seen as somewhat of a taboo by the interviewed men. The attitudes towards routine and habitual online abuse are internalised, as this is a system that journalists have been socialised into and it is just "part of the job". The logic of the vicious circle is applied - everybody else can handle it, so consequently, I must handle it. Sharing horror-stories about online trolls among colleagues is obviously a sign of camaraderie and belonging, but usually conversation is not heavily focused on how to cope with the situation, but instead communicated as "you-will-not-believe-what-happened-to-me" 
anecdotes. Ignoring the seriousness of incidents or relying on humour is just a defence against "feedback" that actually hurts. Yet again, such an attitude towards incidents and verbal sharing contribute to the culture within the newsroom, where honest descriptions of emotions and expressing a need for support are neglected.

Simultaneously and quite paradoxically, our interviews revealed that male journalists are open to seeking professional help and making use of communicative strategies, but the system lacks proper support measures. There is willingness to share and perceived usefulness of talking about the abuse with a psychologist or a therapist, as this is considered an acceptable way to unload the stress. None of the participants had used this opportunity, though. Theoretically, we can notice some shifts in hegemonic masculinity, but they do not translate very successfully into actual practices if the social and organisational structures do not offer support and encouragement.

\section{Conclusion}

The aim of this article was to examine Estonian male journalists' experiences with abusive online communication in the context of gender expectations and norms. Based on the analysis of data collected via qualitative interviews, we see that abusive and harrassive online communication has been normalised to a great extent and dealing with e-bile, personal attacks and intimidation has become a part of the professional routine. Typically, the attacks can be labelled as belonging in three categories: questioning their (1) specific skills/competence (“illiterate!"), (2) general knowledge/education (“uneducated!"), and (3) age/generation stereotypes ("snowflake!"). As noted in other studies (Chen et al. 2018), journalists often grow accustomed to receiving threats, abuse and insults online, saying that one must simply have "thick skin" since receiving so-called negative feedback is part of the job.

Hegemonic masculinity as an operational accepted framework became evident in many cases. Male journalists are especially affected by abuse that makes use of punitive mockery and ridicule or comments that target their masculinity (as being easily-offended, emotional, empathetic, left-leaning and not (yet)-a-man). They seek additional information about the offenders to determine the power dynamics and hierarchies, to gain control, and they emulate the strong, silent, rational male - who avoids "complaining" - ideal coping discourse. A version of "complicit masculinity" (Connell 1987) seems to be widely accepted and we could reframe it as an opportunity. Embodying complicit masculinity implies that there is room for reflection and change, at least on a theoretical level. The journalists admitted they perceive the unjustness and overwhelming stress of conforming to hegemonic masculinity by being pressured into this ideal. The journalists expressed fatigue, disappointment and the need for psychological support, currently lacking in media organisations. Furthermore, as Ivask (2020) has suggested, journalists' unions should start discussions with newsroom managers to develop strategies as to how comments could and should be moderated online.

More broadly, however, this study not only draws attention to the challenges of the newsroom and journalists, but also raises questions about the obligation of (media) organisations to protect their employees. Many professions increasingly rely upon involving and attracting wider audiences, becoming more and more transparent and interactive 
(Webster 2014), making workers and professionals from many fields individually more easily accessible to the public, including the abusive members of it. Future research could explore how journalists and newsrooms can develop specific solutions, which can then be tested in other contexts. Solutions and structures aimed at safeguarding mental health and emotional well-being must consider the potential barriers and pitfalls stemming from rigid gender stereotypes and the cultural frame of hegemonic masculinity.

\section{References}

Abedinifard, Mostafa. 2016. "Structural Functions of the Targeted Joke: Iranian Modernity and the Qazvini Man as Predatory Homosexual." International Journal of Humor Research 29(3): 337-357.

Adams, Catherine. 2018. “"They Go for Gender First': The Nature and Effect of Sexist Abuse of Female Technology Journalists.” Journalism Practice 12(7): 850-869.

Berger, Leigh. 2001. "Inside out: Narrative Autoethnography as a Path toward Rapport." Qualitative Inquiry 7(4): 504-518.

Berger, Peter L. and Thomas Luckmann. 1966. The Social Construction of Reality: A Treatise in the Sociology of Knowledge. Garden City: Anchor Books.

Braun, Virginia and Victoria Clarke. 2006. "Using Thematic Analysis in Psychology." Qualitative Research in Psychology 3(2): 77-101.

Buchanan, Marla and Patrice Keats. 2011. "Coping with Traumatic Stress in Journalism: A Critical Ethnographic Study.” International Journal of Psychology 46(2): 127-35.

Burcar, Veronika. 2014. "Masculinity and Victimization: Young Men's Talk about Being Victims of Violent Crime.” Pp. 113-130 in Masculinities in the Criminological Field, edited by Ingrid Lander, Signe Ravn, and Nina Jon. London: Routledge.

Chen, Gina M., Paromita Pain, Victoria Y. Chen, Madlin Mekelburg, Nina Springer, and Franziska Troger. 2018. "“You Really Have to Have a Thick Skin': A Cross-Cultural Perspective on How Online Harassment Influences Female Journalists.” Journalism 21(7): 877-895.

Citron, Danielle K. and Helen L. Norton. 2011. "Intermediaries and Hate Speech: Fostering Digital Citizenship for Our Information Age.” Boston University Law Review 91(4): 1435-1484.

Citron, Danielle K. 2009. “Law's Expressive Value in Combating Cyber Gender Harassment.” Michigan Law Review 108(3): 373-415.

Citron, Danielle K. 2014. Hate Crimes in Cyberspace. Cambridge, MA: Harvard University Press.

Connell, Raewyn W. 1987. Gender and Power: Society, the Person and Sexual Politics. Cambridge: Polity Press.

Detel, Hanne. 2013. "Disclosure and Public Shaming in the Age of New Visibility." Pp. 77-96 in Media and Public Shaming: Drawing the Boundaries of Disclosure, edited by Julian Petley. London: I. B. Tauris \& Co.

Dickson-Swift, Virginia, Erica L. James, Sandra Kippen, and Pranee Liamputtong. 2007. "Doing Sensitive Research: What Challenges Do Qualitative Researchers Face?” Qualitative Research 7(3): 327-53.

Edelman. 2021. "2021 Edelman Trust Barometer Special Report: Trust and the Coronavirus." Retrieved February 28, 2021 (https://www.edelman.com/sites/g/files/aatuss191/files/2021-01/2021-edelmantrust-barometer.pdf).

European Institute for Gender Equality (EIGE). 2018. "Study and Work in the EU: Set Apart by Gender." Retrieved February 15, 2021 (https://eige.europa.eu/publications/study-and-work-eu-set-apartgender-report). 
Fletcher, Joyce K. 1998. “Relational Practice:AFeminist Reconstruction of Work.” Journal of Management Inquiry 7(2): 163-186.

Folkman, Susan and Richard S. Lazarus. 1988. "Coping as a Mediator of Emotion.” Journal of Personality and Social Psychology 54(3): 466-475.

Fortuna, Paula, Juan Soler-Company, and Leo Wanner. 2020. “Toxic, Hateful, Offensive or Abusive? What Are We Really Classifying? An Empirical Analysis of Hate Speech Datasets". Pp. 67866794 in Proceedings of the 12th Conference on Language Resources and Evaluation. Marseille: European Language Resources Association.

Goldberg, Hern. 1976. The Hazard of Being Male: Surviving the Myth of Masculine Privilege. New York: Nash.

Griffith, Alison I. 1998. "Insider/Outsider: Epistemological Privilege and Mothering Work." Human Studies 21(4): 361-376.

Gudipaty, Nagamallika. 2017. "Gendered Public Spaces. Online Trolling of Women Journalists in India." Comunicazione politica 18(2): 299-310.

Hardin, Marie and Stacie Shain. 2005. "Female Sports Journalists: Are We There Yet? 'No'.” Newspaper Research Journal 26(4): 22-35.

Hardin, Marie and Stacie Shain. 2006. "'Feeling Much Smaller than You Know You Are': The Fragmented Professional Identity of Female Sports Journalists." Critical Studies in Media Communication 23(4): 322-338.

Hedman, Ulrika and Monica Djerf-Pierre. 2013. "The Social Journalist: Embracing the Social Media Life or Creating a New Digital Divide?” Digital Journalism 1(3): 368-385.

Ivask, Signe. 2020. "A Way to Silence Journalists? Estonian Female Journalists' Experiences with Harassment and Self-Censorship.” Pp. 114-130 in Journalist Safety and Self-Censorship, edited by Rpy Krøvel, Anna M. Grøndahl Larsen, and Ingrid Fadnes. London: Routledge.

Jane, Emma A. 2015. "Flaming? What Flaming? The Pitfalls and Potentials of Researching Online Hostility." Ethics and Information Technology 17(1): 65-87.

Jane, Emma A. 2014. “'Back to the Kitchen, Cunt': Speaking the Unspeakable about Online Misogyny." Continuum 28(4): 558-570.

Krause, Rüdiger. 2018. ““Always-on': The Collapse of the Work-Life Separation in Recent Developments, Deficits and Counter-Strategies.” Pp. 223-248 in Working in Digital and Smart Organizations, edited by Edoardo Ales, Ylenia Curzi, Tommaso Fabbri, Olga Rymkevich, Iacopo Senatori, Giovanni Solinas. Cham: Palgrave Macmillan.

Lee, Eun-Ju and Edson C. Tandoc Jr. 2017. "When News Meets the Audience: How Audience Feedback Online Affects News Production and Consumption: When News Meets the Audience." Human Communication Research 43(4): 436-449.

Lewis, Ruth, Michael Rowe, and Clare Wiper. 2017. "Online Abuse of Feminists as an Emerging Form of Violence against Women and Girls.” The British Journal of Criminology 57(6): 1462-1481.

Lewis, Seth C., Rodrigo Zamith, and Mark Coddington. 2020. "Online Harassment and Its Implications for the Journalist-Audience Relationship.” Digital Journalism 8(8): 1047-67.

Luque, Javier and Henri Mikael Koponen. 2017. "Journalists in Finland Face 'Unprecedented' Levels of Online Abuse.” International Press Institute. Retrieved April 14, 2020 (https://ipi.media/ journalists-in-finland-face-unprecedented-levels-of-online-abuse/).

Marling, Raili. 2017. "Gender Equality in Estonia." Pp. 246-260 in Gender Equality in a Global Perspective, edited by Anders Ortenblad, Raili Marling, and Snjezana Vasiljevic. New York: Routledge.

McKenzie, Sarah K., Sunny Collings, Gabrielle Jenkin, and Jo River. 2018. "Masculinity, Social Connectedness, and Mental Health: Men's Diverse Patterns of Practice." American Journal of Men's Health 12(5): 1247-1261. 
Moloney, Mairead E. and Tony P. Love. 2018. “Assessing Online Misogyny: Perspectives from Sociology and Feminist Media Studies.” Sociology Compass 12(5): 1-12.

Murumaa-Mengel, Maria and Andra Siibak. 2019. "Compelled to be an Outsider: How Students on a Social Media Detox Self-Construct Their Generation.” Comunicazioni sociali 2: 263-275.

Nilsson, Monica Löfgren and Henrik Örnebring. 2016. "Journalism Under Threat: Intimidation and Harassment of Swedish Journalists." Journalism Practice 10(7): 880-890.

North, Louise. 2016. "Damaging and Daunting: Female Journalists' Experiences of Sexual Harassment in the Newsroom." Feminist Media Studies 16(3): 495-510.

Metcalf, Katrin N. 2019. "How to Build E-Governance in a Digital Society: The Case of Estonia." Revista Catalana de Dret Públic (58): 1-12.

O'Sullivan, Patrick B. and Andrew J. Flanagin. 2003. "Reconceptualizing 'Flaming' and Other Problematic Messages.” New Media \& Society 5(1): 69-94.

Obermaier, Magdalena, Michaela Hofbauer, and Carsten Reinemann. 2018. "Journalists as Targets of Hate Speech. How German Journalists Perceive the Consequences for Themselves and How They Cope with It." Studies in Communication and Media 7(4): 499-524.

Pärson, Tiina. 2018. "The Use of Sharing Economy Services is Growing." Statistics Estonia. Retrieved April 14, 2020 (https://www.stat.ee/en/uudised/news-release-2018-100).

Post, Senja and Hans M. Kepplinger. 2019. "Coping with Audience Hostility. How Journalists' Experiences of Audience Hostility Influence Their Editorial Decisions.” Journalism Studies 20(16): 2422-2442.

Reporters Without Border. 2017. "Reporters Without Borders: Safety Guide for Journalists." Retrieved February 19, 2021 (https://rsf.org/sites/default/files/safety_guide_2017.pdf).

Reynard, Leslie. 2019. "Troll Farm: Anonymity as a Weapon for Online Character Assassination." Pp. 392-419 in Advances in Media, Entertainment, and the Arts. Handbook of Research on Deception, Fake News, and Misinformation Online, edited by Innocent E. Chiluwa and Sergei A. Samoilenko. Hershey: IGI Global.

Robertson, Steve. 2007. Understanding Men and Health: Masculinities, Identity and Well-Being. McGraw-Hill Education.

Robinson, Sally. 2000. Marked Men: White Masculinity in Crisis. Columbia University Press.

Rosa, Hartmut. 2013. Social Acceleration: A New Theory of Modernity. Columbia University Press.

Shanahan, Marie K. 2017. Journalism, Online Comments, and the Future of Public Discourse. New York: Routledge.

Shin, Wooyeol, Changwook Kim, and Jaewon Joo. 2020. "Hating Journalism: Anti-Press Discourse and Negative Emotions toward Journalism in Korea." Journalism (online first).

Stahel, Lea and Constantin Schoen. 2020. "Female Journalists under Attack? Explaining Gender Differences in Reactions to Audiences' Attacks.” New Media \& Society 22(10): 1849-1867.

Statistics Estonia. 2019. “Gender Pay Gap.” Retrieved February 28, 2021 (https://www.stat.ee/en/findstatistics/statistics-theme/work-life/wages-and-salaries-and-labour-costs/gender-pay-gap).

Kütt, Kadri. 2021. "Population Increased but Births Continued to Fall." Statistics Estonia. Retrieved February 28, 2021 (https://www.stat.ee/en/node/183337).

Suler, John. 2005. “The Online Disinhibition Effect." International Journal of Applied Psychoanalytic Studies 2(2): 184-188.

Law Commission. 2018. Abusive and Offensive Online Communications: A Scoping Report. Law Commission.

Tsuda, Takeyuki. 2020. "What Makes Hegemonic Masculinity so Hegemonic? Japanese American Men and Masculine Aspirations." Identities 1-20.

Webster, Frank. 2014. Theories of the Information Society. 4th edition. London: Routledge. 
Worlds of Journalism. 2016. "Aggregated Tables for Key Variables (2012-2016). Socio-demographic Backgrounds.” Retrieved 14 April, 2020 (https://worldsofjournalism.org/data-d79/data-and-keytables-2012-2016/).

Zanjani, Faika and Graham D. Rowles. 2012. “'We Don't Want to Talk about That': Overcoming Barriers to Rural Aging Research and Interventions on Sensitive Topics." Journal of Rural Studies 28(4): 398-405.

Ziegele, Marc, Nina Springer, Pablo Jost, and Scott Wright. 2017. "Online User Comments across News and Other Content Formats: Multidisciplinary Perspectives, New Directions." Studies in Communication and Media 6(4): 315-332.

\section{Authors}

Armas Riives is currently on his way to obtaining a Master's degree in Journalism and Communication at the University of Tartu in Estonia. His line of research focuses on aggressive and abusive communication against journalists. He has worked in the field of communication management in both the public and private sectors. For the past few years he has worked as a writing journalist with one of the largest daily newspapers in Estonia.

Contact: armas.riives@ut.ee

Maria Murumaa-Mengel ( $\mathrm{PhD}$ in media and communication) is working as an Associate Professor of Media Studies at the Institute of Social Studies, University of Tartu. In her research she is focusing mainly on people's use (and non-use, or going "off the grid ") of social media. Recently, she has looked into how online risks (e.g. "online perverts", e-bile) and opportunities (e.g. microcelebrity) are changing communication and cultural norms for various groups.

Contact: maria.murumaa@ut.ee

Signe Ivask ( $\mathrm{PhD}$ in media and communication) is a postdoctoral researcher at Masaryk University, Czechia. Her research interests include the well-being of journalists, routines in the newsroom, and media sociology. Her latest work focuses on journalistic selfcensorship. She has expertise as a newspaper and radio journalist.

Contact: signeivask@mail.muni.cz 